\title{
Diagnosing and monitoring non-alcoholic fatty liver disease in adults
}

Christopher D. Byrne ${ }^{1,2}$, Janisha Patel ${ }^{3}$, Eleonora Scorletti ${ }^{1,2}$, Giovanni Targher ${ }^{4}$

${ }^{1}$ Nutrition and Metabolism, Faculty of Medicine, University of Southampton, UK

${ }^{2}$ Southampton National Institute for Health Research Biomedical Research Centre, University Hospital Southampton, Southampton General Hospital, Tremona Road, Southampton SO16 6YD, UK

${ }^{3}$ Department of Hepatology, Southampton General Hospital, Tremona Road, Southampton SO16 6YD, UK

${ }^{4}$ Department of Medicine, Section of Endocrinology, Diabetes and Metabolism, University and Azienda Ospedaliera Universitaria Integrata of Verona, Piazzale Stefani 1, 37126 Verona, Italy

\section{Conflict of Interests:}

All authors have no conflicts of interest to disclose

Address for correspondence:

Professor Chris. Byrne

Professor Endocrinology \& Metabolism

Nutrition and Metabolism, Faculty of Medicine

IDS Building, MP 887

University of Southampton

Southampton SO16 6YD, UK

E-mail: cdtb@soton.ac.uk

Phone: +44 2381208818 
Word count: 1199 words; Boxes: 8; Figures: 1; References: 39

At a routine health check arranged by his company, a 52 year-old sedentary male computer programmer was found to have a serum alanine aminotransferase (ALT) concentration of 68 $\mathrm{IU} / \mathrm{L}$ (normal 0-40 IU/L), and a triglyceride concentration of $1.9 \mathrm{mmol} / \mathrm{L}$. His fasting plasma glucose levels were $5.8 \mathrm{mmol} / \mathrm{L}$ and other basic liver, renal and lipid blood tests were normal. $\mathrm{He}$ had an unremarkable medical history and took no regular medications, did not smoke and consumed $<7$ units of alcohol/week. Clinical examination was unremarkable. His body mass index was $29 \mathrm{~kg} / \mathrm{m}^{2}$; waist circumference $102 \mathrm{~cm}$ and blood pressure $134 / 88 \mathrm{mmHg}$.

\section{What is the next investigation?}

His general practitioner requested a liver ultrasonography (confirming the presence of hepatic steatosis) and a repeat serum ALT measurement was $62 \mathrm{IU} / \mathrm{L}$. Other blood tests (including serology for hepatitis $B$ and $C$ viruses, liver auto-antibodies and ferritin) excluded other causes of liver dysfunction. The patient is likely to have non-alcoholic fatty liver disease (NAFLD).

Box 1 describes how patients with NAFLD usually present. When LFTs (e.g. serum aminotransferases such as serum ALT levels) are increased (above the laboratory recommendation for the upper limit of normal), patients should be further investigated to diagnose (or exclude) NAFLD. Figure 1 illustrates a potential investigative pathway for diagnosing NAFLD and for identifying other common causes of chronic liver disease.

When patients have any of the common cardiometabolic risk factors shown in Box 2 plus abnormal LFTs, it is likely the diagnosis is NAFLD (in the absence of other risk factors for liver disease shown in Box 3).

\section{Introduction}

NAFLD encompasses a spectrum of progressive liver conditions, ranging from non-alcoholic fatty liver (NAFL) to steatohepatitis (NASH), fibrosis and cirrhosis. NAFLD is an important condition for clinicians and patients, because it not only has the potential for causing chronic serious liver disease, but it also may adversely influence diabetes and cardiovascular disease. NAFLD is the commonest liver disease in high-income countries, and is estimated to affect at least $25 \%-30 \%$ of adults in the general population and up to $70 \%-90 \%$ of persons with obesity or T2DM ${ }^{1}$. NAFLD is associated not only with liver-related morbidity and mortality, but also with an increased risk of developing fatal and nonfatal cardiovascular disease (CVD), T2DM and chronic kidney disease ${ }^{23}$.

This rational testing article discusses the evidence for the different investigations currently available to diagnose and monitor NAFLD. The article highlights the variation in international guidelines (European, US and NICE) ${ }^{4-6}$, particularly regarding the use of liver ultrasonography. Treatment options are beyond the scope of this article.

\section{When to suspect NAFLD?}

NAFLD is usually a 'silent' disease. Suspect NAFLD if the patient:

- is overweight or obese (although NAFLD can occur in lean individuals)

- $\quad$ has T2DM or metabolic syndrome ${ }^{7}$

- has incidentally discovered abnormal LFTs with mild-to-moderate elevations of serum aminotransferase levels. However, it should be noted that serum aminotransferase 
levels are not sensitive or specific enough to exclude (or identify) NAFLD, especially in those with T2DM

- it is not recommended that patients with metabolic risk factors and normal LFTs are further investigated for NAFLD (although the European guidelines recommended that patients with type 2 diabetes or metabolic syndrome should undergo diagnostic procedures for the diagnosis of NAFLD ${ }^{4}$.

\section{How to investigate and diagnose NAFLD?}

There are a number of methods to diagnose NAFLD (Box 4).

Liver biopsy is the reference method for diagnosing NAFLD, with most accurate assessment of disease grade and stage of liver fibrosis $(0 \text { to } 4)^{89}$. However, liver biopsy is a risky, potentially painful and costly procedure ${ }^{10}$. Undertaking serial liver biopsies over time is therefore unacceptable to monitor disease progression. Nevertheless, biopsy is the only method for diagnosing NASH (as there are no good biomarkers for detecting NASH), and a biopsy may be necessary if other chronic liver diseases cannot be excluded.

Ultrasonography is the first-line imaging technique for diagnosing NAFLD. Compared to histology, ultrasonography has good sensitivity ( $85 \%)$ and excellent specificity $(\sim 95 \%)$ for detecting moderate hepatic steatosis ${ }^{11},{ }^{12}$. However, ultrasonography has poor sensitivity for detecting low levels of liver fat infiltration (e.g. when $<20 \%$ of hepatocytes are steatotic) ${ }^{13}$. In the UK the recent NICE guidelines concluded that ultrasonography was 'not cost effective ${ }^{6}$ for detecting hepatic steatosis, despite there is widespread acceptance that ultrasonography is the most useful imaging technique to detect hepatic steatosis ${ }^{4514}$. (N.B. European and US Guidelines recommend that the presence of hepatic steatosis should be always confirmed with imaging techniques such as ultrasonography).

Other imaging - Computed tomography $(\mathrm{CT})$ and magnetic resonance imaging (MRI can be used to detect hepatic steatosis, but such imaging techniques are more expensive and less readily available $e^{1,2}$. Whereas MRI has much better sensitivity than ultrasonography to detect low levels of liver fat, CT has essentially similar sensitivity to ultrasonography, but exposes the patient to low levels of radiation. Therefore, ultrasonography should be considered the first-line imaging technique for detecting liver fat.

Non-invasive biomarkers of steatosis (e.g., fatty liver index) have a limited clinical utility, as they often do not accurately quantify steatosis as assessed histologically. Controlled attenuation parameter (CAP, assessed by transient elastography) can also be used, although it remains uncertain what CAP thresholds should be adopted to diagnose steatosis ${ }^{15}$.

\section{Monitoring for hepatic fibrosis}

Liver fibrosis cannot be accurately detected by ultrasonography and diagnosis requires the use of either liver biopsy or non-invasive tests ${ }^{516}$ (summarized in Box 5). As many as a third of patients with NAFL develop liver fibrosis ${ }^{17}{ }^{18}$, and the annual fibrosis progression rate is about one histological stage (from 0 to 4) over 14.3 years for patients with NAFL and 7.1 years for those with NASH, respectively. Advanced hepatic fibrosis (histological stage 3 or 4 ) strongly predicts risk of developing end-stage liver disease and hepatocellular carcinoma ${ }^{19-}$ ${ }^{22}$ and these patients therefore need identifying and referring to secondary care. This level of hepatic fibrosis can now be detected by non-invasive biomarker tests with a sufficiently high sensitivity and specificity, and therefore these non-invasive tests should be implemented and used in primary care to identify those patients with advanced hepatic fibrosis who require 
referral to secondary care specialists. The NICE Guidelines recommended the use of the ELF test (see Figure 1), but where this blood test is not available other non-invasive biomarker score tests could be easily used such as Fibrosis-4 score (FIB-4) or NAFLD Fibrosis score (see Box 5). (These two scores can be calculated using freely available simple online calculators, which require input of simple anthropometric and biochemical measurements). The performances of the ELF test, FIB-4 and NAFLD Fibrosis score to diagnose advanced fibrosis ( $\geq F 3$ stage) are summarised from several studies in NAFLD ${ }^{23}$ and are shown in Box 6.

When levels of hepatic fibrosis are below those indicated in Figure 1 and Box 5, re-testing after $\sim 3$ years is recommended in line with the NICE Guidelines.

\section{Pragmatic approach}

Figure. 1 is a suggested pragmatic flow diagram for the diagnosis and monitoring of NAFLD in asymptomatic adult patients in primary and non-specialist secondary care. The diagram contains 'red flag' boxes, boxes to guide investigation and boxes to indicate points in the flow diagram at which we would recommend seeking a Specialist opinion. However, it is important to underline that a validated, widely accepted, flow diagram for the diagnosis and monitoring of NAFLD does not yet exist.

\section{Evidence into Practice Box}

- When and in whom should NAFLD be suspected?

- How should the presence of liver fat and liver fibrosis be diagnosed?

- Which patients with NAFLD need to be referred for specialist opinion and care?

\section{Acknowledgments}

The authors thank Ms Irene McGill and Ms Jane Putsey Mull for their helpful comments and advice during the writing of this article. Ms Irene McGill and Ms Jane Putsey Mull are expert patients with NAFLD, who previously participated as Committee members in the writing of the NICE NAFLD guidelines (ng 49).

\section{Contribution.}

All authors fulfil all four ICMJE criteria for authorship.

\section{Competing interests statement}

All authors have completed the ICMJE uniform disclosure form and declare: no support from any organisation for the submitted work, no financial relationships with any organisations that might have an interest in the submitted work in the previous three years, and no other relationships or activities that could appear to have influenced the submitted work. 


\section{Licence for Publication}

The Corresponding Author has the right to grant on behalf of all authors and does grant on behalf of all authors, an exclusive licence (or non exclusive for government employees) on a worldwide basis to the BMJ Publishing Group Ltd to permit this article (if accepted) to be published in BMJ and any other BMJPGL products and sublicences such use and exploit all subsidiary rights, as set out in our licence (http://group.bmi.com/products/journals/instructions-for-authors/licence-forms). 


\section{FIGURE LEGEND}

Fig. 1 - A pragmatic flow diagram for diagnosing and monitoring NAFLD in adults in clinical practice.

Staging of hepatic fibrosis can be undertaken with the use of either biopsy (the "gold standard") or various non-invasive tests. The Enhanced Liver Fibrosis (ELF) blood test (recommended by the NICE Guidelines) has an excellent accuracy in distinguishing advanced fibrosis and cirrhosis. In the case of a patient with an intermediate ELF blood test score (ranging from 7.8 to 10.51), further investigation with vibration controlled transient elastography (FibroScan) could be also considered. The use of the ELF blood test is not recommended or adopted in any country outside the UK or in any international society practice guidelines. So, if the ELF blood testing is not available, a Fibrosis-4 (FIB4) score $>2.67$; a NAFLD fibrosis score (NFS) score $>0.676$ or a second-line test such as the vibration controlled transient elastography (FibroScan) (see Box 5) can be used (singly or in combination) to identify those individuals with advanced hepatic fibrosis that must be referred to specialists in hepatology. The combination of the FibroScan with FIB4/NFS measurements has shown an excellent accuracy in distinguishing advanced fibrosis ${ }^{16}$. Comprehensive review articles of drug treatment options for NAFLD have been published elsewhere ${ }^{45}$. 


\section{Box 1}

How do patients with NAFLD usually present?

\section{Common presentations potentially suggestive of NAFLD}

Incidental finding of increased levels (above the upper limit of normal) of serum ALT or AST or both (with other LFTs otherwise normal) and alcohol intake $<21$ standard drinks per week in men or $<14$ standard drinks per week in women

LFTs noted to be abnormal as above prior to treatment with a statin for increased cardiovascular risk

Fatigue and LFTs noted to be abnormal as above

LFTs checked as part of investigation of patients with other diseases (e.g. diabetes, obesity, metabolic syndrome, cardiovascular disease)

LFTs being monitored for other conditions or treatments

Incidental finding of hepatic steatosis noted on ultrasound examination of abdomen 


\section{Box 2}

Common cardiometabolic risk factors for non-alcoholic fatty liver disease (NAFLD).

\begin{tabular}{|c|c|c|}
\hline Overweight/obesity & & $\begin{array}{l}\text { Apply ethnic-specific cut offs } \\
\text { for body mass index (BMI) } \\
\text { e.g., white European } \\
\geq 25 / \geq 30 \mathrm{~kg} / \mathrm{m}^{2}\end{array}$ \\
\hline \multirow{5}{*}{ Metabolic Syndrome features } & Abdominal obesity & $\begin{array}{l}\text { Apply ethnic-specific cut offs } \\
\text { for waist circumference } \\
\text { e.g., white European } \\
>94 / 80 \mathrm{~cm}(\mathrm{M} / \mathrm{F}) \\
\end{array}$ \\
\hline & High serum triglycerides & $\begin{array}{l}\geq 1.7 \mathrm{mmol} / \mathrm{l} \text { or lipid-lowering } \\
\text { treatment }\end{array}$ \\
\hline & $\begin{array}{l}\text { Increased blood } \\
\text { pressure/ hypertension }\end{array}$ & $\begin{array}{l}\geq 130 / 85 \mathrm{mmHg} \text { or anti- } \\
\text { hypertensive treatment }\end{array}$ \\
\hline & Low HDL-cholesterol & $<1.0 / 1.3 \mathrm{mmol} / \mathrm{l}(\mathrm{M} / \mathrm{F})$ \\
\hline & $\begin{array}{ll}\text { Impaired } & \text { fasting } \\
\text { glycaemia } & \\
\end{array}$ & $\begin{array}{l}\text { Fasting glucose levels } \geq 5.6 \\
\mathrm{mmol} / \mathrm{l}\end{array}$ \\
\hline Type 2 diabetes mellitus & & $\begin{array}{l}\text { Fasting glucose levels } \geq 7 \\
\text { mmol/l or glucose-lowering } \\
\text { treatment }\end{array}$ \\
\hline
\end{tabular}

Other modifiable risk factors for NAFLD are cigarette smoking (due to its pro-fibrotic hepatic effect), excessive dietary intakes of fructose, carbohydrates and saturated fatty acids.

N.B. NAFLD can also occur in lean individuals (the so-called "lean NAFLD"). 


\section{Box 3}

Risk factors for liver disease to exclude in diagnosing NAFLD.

\begin{tabular}{|c|c|}
\hline Risk factors for liver disease & $\begin{array}{l}\text { History/initial test results } \\
\text { suggestive of alternative diagnoses }\end{array}$ \\
\hline $\begin{array}{l}>21 \text { standard drinks per week in men } \\
\text { and }>14 \text { standard drinks per week in women } \\
\left(\text { see footnote }{ }^{*}\right)\end{array}$ & History of excessive alcohol consumption \\
\hline $\begin{array}{l}\text { Drugs } \\
\text { e.g. valproic acid, oestrogens, tamoxifen, } \\
\text { corticosteroids, tetracycline, amiodarone, } \\
\text { perhexiline maleate, methotrexate, } 4,4^{\prime}- \\
\text { diethylaminoethoxyhexesterol, chloroquine, } \\
\text { L-asparaginase }\end{array}$ & History of drug exposure \\
\hline Viral hepatitis & $\begin{array}{l}\text { Serological positivity for } \\
\text { HBsAg and anti-HCV antibodies/HCV- } \\
\text { RNA }\end{array}$ \\
\hline Haemochromatosis & $\begin{array}{l}\text { High transferrin saturation }(>45 \%) \\
\text { High serum ferritin }(>1000 \mathrm{mcg} / \mathrm{l})\end{array}$ \\
\hline Autoimmune hepatitis & $\begin{array}{l}\text { Serum } \\
\text { Immunoglobulins (lgG) raised } \\
\text { Anti-mitochondrial antibodies +ve } \\
\text { Smooth muscle cell antibodies strongly } \\
+ \text { +ve } \\
\text { Anti-nuclear antibodies +ve } \\
\text { Anti-liver kidney microsomal +ve }\end{array}$ \\
\hline Wilson's disease & Low level of caeruloplasmin (<200 mg/l) \\
\hline Alpha 1 anti-trypsin deficiency & $\begin{array}{l}\text { Low level of alpha } 1 \text { anti-trypsin protein } \\
(<260 \mathrm{micromol} / \mathrm{l})\end{array}$ \\
\hline Coeliac disease & $\begin{array}{l}\text { Anti-tissue transglutaminase antibodies } \\
+\mathrm{ve}\end{array}$ \\
\hline Others & $\begin{array}{l}\text { Occupational exposure to hepatoxins } \\
\text { Malnutrition (especially Kwashiokor) } \\
\text { Total parenteral nutrition } \\
\text { Rapid weight loss } \\
\text { Surgically altered bowel anatomy } \\
\text { (e.g. jejuno-ileal bypass, extensive small- } \\
\text { bowel resection) } \\
\text { Lipodystrophy } \\
\text { Hypobetalipoproteinemia }\end{array}$ \\
\hline
\end{tabular}

ording to the US National Institute on Alcohol Abuse and Alcoholism (NIAAA), a standard alcoholic drink is any drink that contains about 14 grams of pure alcohol. A unit of alcohol $=8$ grams of alcohol. Of note, the alcohol thresholds for liver disease reported in the Table are not congruent with the UK current thresholds for safe alcohol consumption, which are $<14$ units per week in both men and women.

N.B.: Low titers of anti-nuclear, anti-smooth muscle and anti-mitochondrial antibodies can be noted in patients with NAFLD (in the absence of autoimmune hepatitis). Similarly, slightly lower caeruloplasmin levels can be also found. 


\begin{tabular}{|c|c|c|}
\hline Technique & Result compatible with NAFLD & Pros and Cons of technique \\
\hline Biopsy & $\begin{array}{l}\text { Histological examination shows lipid } \\
\text { droplets in at least } 5 \% \text { of hepatocytes }\end{array}$ & $\begin{array}{l}\text { Reference method for diagnosing } \\
\text { NAFLD and where there is diagnostic } \\
\text { uncertainty. Expensive, invasive, } \\
\text { significant morbidity and even } \\
\text { mortality. Not suitable for monitoring } \\
\text { of disease }\end{array}$ \\
\hline Ultrasonography & $\begin{array}{l}\text { Liver echogenicity exceeds that of renal } \\
\text { cortex and spleen and there is } \\
\text { attenuation of the ultrasound wave, loss } \\
\text { of definition of the diaphragm, and poor } \\
\text { delineation of the intrahepatic } \\
\text { architecture }\end{array}$ & $\begin{array}{l}\text { Whilst the sensitivity of } \\
\text { ultrasonography is poor below levels } \\
\text { of fatty liver infiltration <20-25\% on } \\
\text { liver histology, ultrasonography is } \\
\text { highly sensitive and specific at higher } \\
\text { levels of fat infiltration. Combining } \\
\text { standard ultrasonography with } \\
\text { computer software technology } \\
\text { (MATLAB) e.g. combined ultrasound } \\
\text { hepatic/renal ratio and hepatic echo- } \\
\text { intensity attenuation rate evaluation }{ }^{24} \text {, } \\
\text { improves the sensitivity of } \\
\text { ultrasonography even further }\end{array}$ \\
\hline $\begin{array}{l}\text { Fatty liver index (FLI) } \\
\text { (Algorithm-derived score utilising body } \\
\text { mass index, waist circumference, fasting } \\
\text { serum triglycerides and gamma- } \\
\text { glutamyltransferase concentrations) }\end{array}$ & $\begin{array}{l}\text { FLI } \geq 60 \text { suggestive of hepatic steatosis } \\
\text { and validated against ultrasonography }{ }^{25}, \\
\text { or } \mathrm{MRS}^{26} \text {. }\end{array}$ & $\begin{array}{l}\text { Inexpensive, but requires waist } \\
\text { circumference measurements. Not } \\
\text { validated against liver histology }\end{array}$ \\
\hline $\begin{array}{l}\text { NAFLD liver fat score } \\
\text { (Algorithm-derived score utilising the } \\
\text { presence of metabolic syndrome and } \\
\text { type } 2 \text { diabetes, fasting serum insulin, } \\
\text { aspartate aminotransferase (AST), and } \\
\text { the AST/alanine aminotransferase ratio }\end{array}$ & $\begin{array}{l}\text { Optimal cut-off point }=-0.640 \text { for } \\
\text { diagnosing hepatic steatosis on } \mathrm{MRS}^{27}\end{array}$ & $\begin{array}{l}\text { Inexpensive, but requires serum insulin } \\
\text { and AST measurements. Not validated } \\
\text { against liver histology }\end{array}$ \\
\hline $\begin{array}{l}\text { Vibration controlled transient } \\
\text { elastography (FibroScan) }\end{array}$ & $\begin{array}{l}\text { Optimal Controlled Attenuation } \\
\text { Parameter (CAP) thresholds } \geq 248, \geq 268 \\
\mathrm{~dB} / \mathrm{m} \text { for those above stage } 1 \text { hepatic } \\
\text { steatosis grade, respectively }^{28}\end{array}$ & $\begin{array}{l}\text { Transient elastography is a promising } \\
\text { technique, but further evidence and } \\
\text { validation of its utility for diagnosing } \\
\text { hepatic steatosis (by CAP } \\
\text { measurement) is required. The signal } \\
\text { can be affected in severely obese } \\
\text { patients }\end{array}$ \\
\hline Computed tomography & $\begin{array}{l}\text { Attenuation of the liver is at least } 10 \\
\text { Hounsfield Units }(\mathrm{HU}) \text { less than that of } \\
\text { the spleen, or attenuation of the liver } \\
\text { less than } 40 \mathrm{HU}^{29}\end{array}$ & $\begin{array}{l}\text { Good for investigating other potential } \\
\text { abdominal pathologies. Computer } \\
\text { tomography has limited sensitivity to } \\
\text { detect low levels (<30\% liver fat } \\
\text { infiltration on liver histology) and } \\
\text { exposes the patient to significant } \\
\text { radiation }\end{array}$ \\
\hline $\begin{array}{l}\text { Magnetic resonance imaging (MRI) } \\
\text { or magnetic resonance spectroscopy } \\
\text { (MRS) }\end{array}$ & $\begin{array}{l}\text { MRI. Chemical shift gradient-echo } \\
\text { imaging with in-phase and opposed- } \\
\text { phase acquisitions identifying } \geq 5.5 \% \text { liver } \\
\text { fat accumulation } \\
\text { MRS. Proton MR spectroscopy identifying } \\
\geq 5.5 \% \text { liver fat accumulation }{ }^{30}\end{array}$ & $\begin{array}{l}\text { MRI and MRS are very sensitive non- } \\
\text { invasive techniques for diagnosing } \\
\text { hepatic steatosis, but are presently } \\
\text { expensive techniques for this } \\
\text { indication }\end{array}$ \\
\hline
\end{tabular}

N.B. Ultrasonography was not recommended in the NICE NAFLD guidelines (ng49) based on a failure of the test (for diagnosing hepatic steatosis) to meet the NICE Quality Adjusted Life Years (QALY) thresholds. However, such a costeffectiveness analysis was not able to take into account that clinicians use liver ultrasonography not only to diagnose liver fat (in the investigation of abnormal liver function tests among suspected cases of NAFLD), but also to exclude other common causes of abnormal liver function tests, such as gallstones or hepatic metastases. Moreover, 
combining standard ultrasonography with computer software technology (MATLAB) e.g. combined ultrasound hepatic/renal ratio and hepatic echo-intensity attenuation rate evaluation ${ }^{24}$, improves the sensitivity of ultrasonography even further. In this methodology, the ultrasound hepatic/renal echo-intensity ratio and ultrasound hepatic echo-intensity attenuation rate were obtained from ordinary ultrasound images using the MATLAB program. Compared with proton-magnetic resonance spectroscopy (i.e., the gold standard for detecting low levels of liver fat content) (see Box 3 ), at levels of $<15 \%$ liver fat content, the sensitivity and specificity of the aforementioned ultrasound quantitative model was $81.4 \%$ and $100 \%$. Of note, the use of liver ultrasonography has also been strongly recommended in the recent British Society of Gastroenterology guidelines for investigating abnormal liver function tests $^{31}$ 


\section{Box 5}

Invasive and non-invasive techniques for diagnosing advanced fibrosis in NAFLD.

\begin{tabular}{|l|l|}
\hline Technique & Result compatible with NAFLD \\
\hline Biopsy & $\begin{array}{l}\text { Advanced fibrosis thresholds }=\text { F3 or F4 } \\
\text { stages } \\
\text { Fibrosis may vary from no fibrosis (F0), portal } \\
\text { fibrosis without septa (F1), portal fibrosis with } \\
\text { few septa (F2), bridging fibrosis between portal } \\
\text { and central veins (F3), and cirrhosis (F4) }\end{array}$ \\
\hline $\begin{array}{l}\text { Liver fibrosis tests } \\
\text { (biochemical variables }+/ \text { - anthropometry) }\end{array}$ & $\begin{array}{l}\text { Advanced fibrosis thresholds } \\
\text { Fibrosis-4 score (FIB4) }>2.67^{32} \\
\text { NAFLD fibrosis score (NFS) }>0.676^{33}\end{array}$ \\
\hline $\begin{array}{l}\text { Transient elastography e.g. FibroScan with M } \\
\text { or XL probes (measurement of 'liver } \\
\text { stiffness') }\end{array}$ & $\begin{array}{l}\text { Advanced fibrosis threshold } \\
\text { Vibration controlled transient } \\
\text { elastography }>8.7 \text { kPA }\end{array}$ \\
\hline $\begin{array}{l}\text { Acoustic radiation force impulse elastography } \\
\text { (ARFI) }\end{array}$ & $\begin{array}{l}\text { Advanced fibrosis threshold } \\
\text { ARFI }>1.4 \text { m/s } / \mathrm{s}^{37}\end{array}$ \\
\hline $\begin{array}{l}\text { Magnetic resonance imaging techniques } \text { e.g. } \\
\text { magnetic resonance-based elastography } \\
\text { (MRE) }\end{array}$ & $\begin{array}{l}\text { Advanced fibrosis threshold } \\
\text { MRE }>3.64^{38}\end{array}$ \\
\hline
\end{tabular}

N.B.: It should be noted that all non-invasive tests for liver fibrosis are better at excluding advanced fibrosis that diagnosing it. N.B.: Patients with NASH may, or may not have significant liver fibrosis. The 'gold standard' for diagnosis of NASH is only liver biopsy, with evidence of hepatocellular ballooning and Mallory bodies.

1. The FIB4 score is calculated as (age $\times$ AST $) \div($ platelet count $\times \sqrt{A L T})$

2. The NFS is calculated as follows: $-1.675+0.037 \times$ age $+0.094 \times \mathrm{BMI}+1.13 \times \mathrm{IR}$ or diabetes (yes $=1, \mathrm{no}=0)+0.99 \times$ AST/ALT ratio $-0.013 \times$ platelet count $-0.66 \times$ serum albumin New thresholds for use of FIB-4 and the NFS have been recently proposed (and validated) for patients aged $\geq 65$ years to exclude the presence of advanced fibrosis (F3 and F4 stages) (FIB-4 $<2.0$, sensitivity $77 \%$ and specificity $70 \%$; NFS $<0.12$, sensitivity $80 \%$ and specificity $70 \%)^{28}$. Conversely, the thresholds of FIB-4 and NFS used in these older patients for identifying the presence of advanced fibrosis remained the same (FIB-4 $>2.67)^{39}$. The NFS is not accurate for excluding advanced fibrosis in individuals aged $<30$ years

3. The ELF score is a commercial blood test that combines quantitative measurements of three serum direct fibrosis biomarkers (i.e. tissue inhibitor of metalloproteinase 1, procollagen III amino terminal peptide and hyaluronic acid) to a single value ${ }^{34}$. In distinguishing moderate fibrosis, a threshold of $\geqslant 10.51$ has an acceptable balance of good sensitivity, specificity, and positive and negative predictive values.

4. In a recent meta-analysis, the summary sensitivities and specificities of FibroScan with the $M$ probe (threshold of 8.7-9.0 kPA) for detecting advanced fibrosis were $87 \%$ and $79 \%$, respectively ${ }^{36}$. A Fibroscan with the XL probe has been also validated for severely obese patients, and has a diagnostic accuracy substantially comparable with that of the standard M probe

5. Magnetic resonance-based elastography (MRE) has the highest diagnostic accuracy for staging fibrosis in NAFLD 


\section{Box 6}

Performance of common non-invasive biomarker scores for advanced hepatic fibrosis ( $\geq F 3$ histological stage).

\begin{tabular}{|l|l|l|l|l|l|}
\hline \multirow{2}{*}{$\begin{array}{l}\text { Biomarker } \\
\text { score }\end{array}$} & \multicolumn{5}{|l|}{ Advanced fibrosis thresholds (F3 or F4 histological stages) } \\
\hline & AUROC & Sens (\%) & Spec (\%) & PPV (\%) & NPV (\%) \\
\hline ELF score & 0.90 & 80 & 90 & 71 & 94 \\
\hline $\begin{array}{l}\text { NAFLD Fibrosis } \\
\text { score (NFS) }\end{array}$ & 0.84 & 77 & 70 & 55 & 90 \\
\hline FIB-4 score & 0.86 & 85 & 65 & 36 & 95 \\
\hline
\end{tabular}

Abbreviations: Sens, sensitivity; Spec, specificity; PPV, positive predictive value; NPV, negative predictive value.

NB: Performance figures are summary estimates from several studies summarised $\mathrm{in}^{23}$. 
Box 7

\section{"What you need to know"}

- When NAFLD is suspected in the presence of abnormal serum liver enzyme levels (in the absence of other competing causes of chronic liver disease), investigate for hepatic steatosis and exclude other liver pathology firstly using liver ultrasonography to diagnose hepatic steatosis and exclude other coexisting liver pathology.

- Once hepatic steatosis has been diagnosed, assess the presence and severity of hepatic fibrosis with the use of non-invasive tests (i.e., biomarker scores and/or vibration controlled transient elastography).

- Refer individuals with suspected advanced hepatic fibrosis to specialists in hepatology for further investigations.

\section{Box 8}

\section{"How this article was made"}

\section{Search strategy}

We searched PubMed for original articles and reviews using the keywords "nonalcoholic fatty liver disease" or "fatty liver" combined with "diagnosis", "prognosis" or "mortality" between 1990 and 2017. Articles published in languages other than English were excluded from the analysis.

CDB and GT wrote the first draft and all authors reviewed and contributed to the writing of the article.

\section{"How patients were involved in the creation of this article"}

Several of our patients have told us of the problem of an inconsistent approach amongst their doctors to investigating their liver disease. Two patient representatives (Ms Irene McGill and Ms Jane Putsey) Mull who have NAFLD and who participated in the NICE NAFLD ng 49 Guideline Development Group commented on the article and gave helpful suggestions to drafts of the manuscript. 


\section{REFERENCES}

1. Younossi ZM, Koenig AB, Abdelatif $D$, et al. Global epidemiology of nonalcoholic fatty liver disease-Metaanalytic assessment of prevalence, incidence, and outcomes. Hepatology 2016;64(1):73-84. doi: 10.1002/hep.28431 [published Online First: 2015/12/29]

2. Byrne CD, Targher G. NAFLD: A multisystem disease. J Hepatol 2015;62(1S):S47-S64. doi: S01688278(14)00933-7 [pii];10.1016/j.jhep.2014.12.012 [doi]

3. Targher G, Byrne CD. Non-alcoholic fatty liver disease: an emerging driving force in chronic kidney disease. Nature reviews Nephrology 2017;13(5):297-310. doi: 10.1038/nrneph.2017.16 [published Online First: 2017/02/22]

4. EASL-EASD-EASO Clinical Practice Guidelines for the management of non-alcoholic fatty liver disease. Diabetologia 2016;59(6):1121-40. doi: 10.1007/s00125-016-3902-y [published Online First: 2016/04/08]

5. Chalasani N, Younossi Z, Lavine JE, et al. The diagnosis and management of nonalcoholic fatty liver disease: Practice guidance from the American Association for the Study of Liver Diseases. Hepatology 2018;67(1):328-57. doi: 10.1002/hep.29367 [published Online First: 2017/07/18]

6. Glen J, Floros L, Day C, et al. Non-alcoholic fatty liver disease (NAFLD): summary of NICE guidance. Bmj 2016;354:i4428. doi: 10.1136/bmj.i4428 [published Online First: 2016/09/09]

7. Alberti KG, Eckel RH, Grundy SM, et al. Harmonizing the metabolic syndrome: a joint interim statement of the International Diabetes Federation Task Force on Epidemiology and Prevention; National Heart, Lung, and Blood Institute; American Heart Association; World Heart Federation; International Atherosclerosis Society; and international association for the Study of Obesity. Circulation 2009;120(16):1640-45. doi: CIRCULATIONAHA.109.192644 [pii];10.1161/CIRCULATIONAHA.109.192644 [doi]

8. Bravo AA, Sheth SG, Chopra S. Liver biopsy. N Eng/ J Med 2001;344(7):495-500. doi: 10.1056/nejm200102153440706 [published Online First: 2001/02/15]

9. Tapper EB, Lok AS. Use of Liver Imaging and Biopsy in Clinical Practice. N Engl J Med 2017;377(8):756-68. doi: 10.1056/NEJMra1610570 [published Online First: 2017/08/24]

10. Rockey DC, Caldwell SH, Goodman ZD, et al. Liver biopsy. Hepatology 2009;49(3):1017-44. doi: 10.1002/hep.22742 [published Online First: 2009/02/27]

11. Hernaez R, Lazo M, Bonekamp S, et al. Diagnostic accuracy and reliability of ultrasonography for the detection of fatty liver: a meta-analysis. Hepatology 2011;54(3):1082-90. doi: 10.1002/hep.24452 [published Online First: 2011/05/28]

12. Ballestri S, Nascimbeni F, Baldelli E, et al. Ultrasonographic fatty liver indicator detects mild steatosis and correlates with metabolic/histological parameters in various liver diseases. Metabolism 2017;72:57-65. doi: 10.1016/j.metabol.2017.04.003 [published Online First: 2017/06/24]

13. Saadeh S, Younossi ZM, Remer EM, et al. The utility of radiological imaging in nonalcoholic fatty liver disease. Gastroenterology 2002;123(3):745-50. [published Online First: 2002/08/29]

14. Wong VW, Chan WK, Chitturi S, et al. The Asia-Pacific Working Party on Nonalcoholic Fatty Liver Disease Guidelines 2017 Part 1: Definition, risk factors and assessment. J Gastroenterol Hepatol 2017 doi: 10.1111/jgh.13857 [published Online First: 2017/07/04]

15. Vuppalanchi R, Siddiqui MS, Van Natta ML, et al. Performance characteristics of vibration-controlled transient elastography for evaluation of nonalcoholic fatty liver disease. Hepatology 2018;67(1):134-44. doi: 10.1002/hep.29489 [published Online First: 2017/09/01]

16. Petta S, Wong VW, Camma C, et al. Serial combination of non-invasive tools improves the diagnostic accuracy of severe liver fibrosis in patients with NAFLD. Aliment Pharmacol Ther 2017;46(6):617-27. doi: 10.1111/apt.14219 [published Online First: 2017/07/29]

17. Fan JG, Kim SU, Wong VW. New trends on obesity and NAFLD in Asia. J Hepatol 2017;67(4):862-73. doi: 10.1016/j.jhep.2017.06.003 [published Online First: 2017/06/24]

18. Singh S, Allen AM, Wang Z, et al. Fibrosis progression in nonalcoholic fatty liver vs nonalcoholic steatohepatitis: a systematic review and meta-analysis of paired-biopsy studies. Clinical gastroenterology and hepatology : the official clinical practice journal of the American 
Gastroenterological Association 2015;13(4):643-54.e1-9; quiz e39-40. doi: 10.1016/j.cgh.2014.04.014 [published Online First: 2014/04/29]

19. Ekstedt $M$, Hagstrom $H$, Nasr $P$, et al. Fibrosis stage is the strongest predictor for disease-specific mortality in NAFLD after up to 33 years of follow-up. Hepatology 2015;61(5):1547-54. doi: 10.1002/hep.27368 [published Online First: 2014/08/16]

20. Hagström $H$, Nasr $P$, Ekstedt $M$, et al. Fibrosis stage but not NASH predicts mortality and time to development of severe liver disease in biopsy-proven NAFLD. Journal of Hepatology 2017 doi: https://doi.org/10.1016/i.jhep.2017.07.027

21. Wong RJ, Aguilar M, Cheung R, et al. Nonalcoholic steatohepatitis is the second leading etiology of liver disease among adults awaiting liver transplantation in the United States. Gastroenterology 2015;148(3):547-55. doi: S0016-5085(14)01474-7 [pii];10.1053/j.gastro.2014.11.039 [doi]

22. Angulo P, Kleiner DE, Dam-Larsen S, et al. Liver Fibrosis, but No Other Histologic Features, Associates With Long-Term Outcomes of Patients With Nonalcoholic Fatty Liver Disease. Gastroenterology 2015 doi: S0016-5085(15)00599-5 [pii];10.1053/j.gastro.2015.04.043 [doi]

23. Chin JL, Pavlides M, Moolla A, et al. Non-invasive Markers of Liver Fibrosis: Adjuncts or Alternatives to Liver Biopsy? Frontiers in pharmacology 2016;7:159. doi: 10.3389/fphar.2016.00159 [published Online First: 2016/07/06]

24. Zhang B, Ding F, Chen T, et al. Ultrasound hepatic/renal ratio and hepatic attenuation rate for quantifying liver fat content. World J Gastroenterol 2014;20(47):17985-92. doi: 10.3748/wjg.v20.i47.17985 [published Online First: 2014/12/31]

25. Bedogni G, Bellentani S, Miglioli L, et al. The Fatty Liver Index: a simple and accurate predictor of hepatic steatosis in the general population. BMC Gatroenterology 2006;6:33.

26. Cuthbertson DJ, Weickert MO, Lythgoe D, et al. External validation of the fatty liver index and lipid accumulation product indices, using $1 \mathrm{H}$-magnetic resonance spectroscopy, to identify hepatic steatosis in healthy controls and obese, insulin-resistant individuals. European journal of endocrinology 2014;171(5):561-9. doi: 10.1530/eje-14-0112 [published Online First: 2014/10/10]

27. Kotronen A, Peltonen $M$, Hakkarainen $A$, et al. Prediction of non-alcoholic fatty liver disease and liver fat using metabolic and genetic factors. Gastroenterology 2009;137(3):865-72. doi: S00165085(09)00913-5 [pii];10.1053/j.gastro.2009.06.005 [doi]

28. Karlas $T$, Petroff $D$, Sasso $M$, et al. Individual patient data meta-analysis of controlled attenuation parameter (CAP) technology for assessing steatosis. J Hepatol 2017;66(5):1022-30. doi: 10.1016/j.jhep.2016.12.022 [published Online First: 2017/01/01]

29. Schwenzer NF, Springer F, Schraml C, et al. Non-invasive assessment and quantification of liver steatosis by ultrasound, computed tomography and magnetic resonance. J Hepatol 2009;51(3):433-45. doi: 10.1016/j.jhep.2009.05.023 [published Online First: 2009/07/17]

30. Szczepaniak LS, Nurenberg P, Leonard D, et al. Magnetic resonance spectroscopy to measure hepatic triglyceride content: prevalence of hepatic steatosis in the general population. AmJPhysiol EndocrinolMetab 2005;288(2):E462-E68. doi: 10.1152/ajpendo.00064.2004 [doi];00064.2004 [pii]

31. Newsome PN, Cramb R, Davison SM, et al. Guidelines on the management of abnormal liver blood tests. Gut 2018;67(1):6-19. doi: 10.1136/gutjnl-2017-314924 [published Online First: 2017/11/11]

32. Shah AG, Lydecker A, Murray K, et al. Comparison of noninvasive markers of fibrosis in patients with nonalcoholic fatty liver disease. Clinical gastroenterology and hepatology : the official clinical practice journal of the American Gastroenterological Association 2009;7(10):1104-12. doi: 10.1016/j.cgh.2009.05.033 [published Online First: 2009/06/16]

33. Angulo $P$, Hui JM, Marchesini $G$, et al. The NAFLD fibrosis score: a noninvasive system that identifies liver fibrosis in patients with NAFLD. Hepatology 2007;45(4):846-54.

34. Guha IN, Parkes J, Roderick P, et al. Noninvasive markers of fibrosis in nonalcoholic fatty liver disease: Validating the European Liver Fibrosis Panel and exploring simple markers. Hepatology 2008;47(2):455-60. doi: 10.1002/hep.21984 [published Online First: 2007/11/27] 
35. Tapper EB, Challies T, Nasser I, et al. The Performance of Vibration Controlled Transient Elastography in a US Cohort of Patients With Nonalcoholic Fatty Liver Disease. Am J Gastroenterol 2016;111(5):67784. doi: 10.1038/ajg.2016.49 [published Online First: 2016/03/16]

36. Xiao G, Zhu S, Xiao X, et al. Comparison of laboratory tests, ultrasound, or magnetic resonance elastography to detect fibrosis in patients with nonalcoholic fatty liver disease: A meta-analysis. Hepatology 2017;66(5):1486-501. doi: 10.1002/hep.29302 [published Online First: 2017/06/07]

37. Cassinotto C, Boursier J, de Ledinghen $V$, et al. Liver stiffness in nonalcoholic fatty liver disease: A comparison of supersonic shear imaging, FibroScan, and ARFI with liver biopsy. Hepatology 2016;63(6):1817-27. doi: 10.1002/hep.28394 [published Online First: 2015/12/15]

38. Loomba R, Wolfson T, Ang B, et al. Magnetic resonance elastography predicts advanced fibrosis in patients with nonalcoholic fatty liver disease: a prospective study. Hepatology 2014;60(6):1920-8. doi: 10.1002/hep.27362 [published Online First: 2014/08/12]

39. McPherson S, Hardy T, Dufour JF, et al. Age as a Confounding Factor for the Accurate Non-Invasive Diagnosis of Advanced NAFLD Fibrosis. Am J Gastroenterol 2017;112(5):740-51. doi: 10.1038/ajg.2016.453 [published Online First: 2016/10/12] 